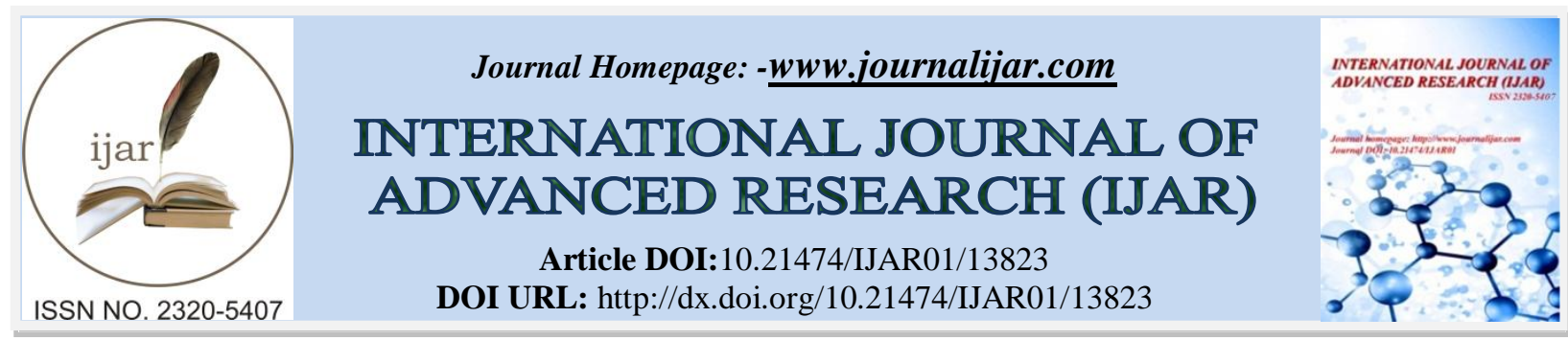

RESEARCH ARTICLE

\title{
PHYTOCHEMICAL SCREENING, TOTAL POLYPHENOLS AND FLAVONOIDS CONTENT AND ANTIRADICAL ACTIVITY OF METHANOLIC EXTRACT OF ANNICKIA CHLORANTHA FROM GABON
}

\section{Joanna Grace Ombouma ${ }^{1}$, Aimé-Jhustelin Abogo Mebale ${ }^{2}$, Daniel-Datch Mefouet Abessolo ${ }^{2}$, Ornella Abessolo $\mathrm{Mve}^{2}$ and Raymonde Mboma ${ }^{3}$}

1. Département de Pharmacologie. Université des Sciences de la Santé (USS), BP : 4009 Libreville (Gabon).

2. Laboratoire Pluridisciplinaire des Sciences (LAPLUS), Ecole Normale Supérieure (ENS), BP :17009, Libreville (Gabon).

3. Département de Biologie et d'Ecologie Végétale. Institut de Recherche en Ecologie Tropicale (IRET), BP : 13354, Libreville (Gabon).

\section{Manuscript Info}

\section{Manuscript History}

Received: 29 September 2021

Final Accepted: 31 October 2021

Published: November 2021

Key words: -

Annickia chlorantha, Methanolicextract, Polyphenols, Flavonoids, Antiradical Activity

\begin{abstract}
In traditional medicine, Annnickia chlorantha (Annonaceae)is used in many parts of Africa to treat several pathologies. It is used for the management of stomach problems, for the treatment of jaundice, tuberculosis, urinary tract infections, malaria, hepatitis and ulcers forms, for gallstones or even diarrhea. The phytochemical analysis and determination of the antiradical activity of the methanolic extract of the trunk bark from Annickia chlorantha from Gabon was the subject of this study. Phytochemical screening revealed the abundance of alkaloids, polyphenols and catechics tannins.The total polyphenol content released by the Folin-Ciocalteu method was 309.17 $\pm 38.05 \mathrm{~g}$ of gallic acid equivalent per $100 \mathrm{mg}$ of dry matterand the total flavonoids content performed with $\mathrm{AlCl}_{3}$ was $155.16 \pm 21.06 \mathrm{~g}$ of quercetin equivalent per $100 \mathrm{mg}$ of dry matter. The antiradical activity was limited to $81.58 \% \pm 1.25$ without disappearance of the $\mathrm{ABTS}^{\circ+}$ radical after 6 minutes of incubation. These results confirm the correlation between the polyphenol content and the antiradical activity.
\end{abstract}

Copy Right, IJAR, 2021,. All rights reserved.

\section{Introduction:-}

In tropical Africa, difficult access to modern medicine, associated with the high cost of drugs, leads nearly $70 \%$ of the population to rely heavily on plants for treatment (NgonoNgane et al., 2011). In 2007, Newman and Cragg demonstrated that two thirds of current drugs have a natural origin (Newman and Cragg, 2007). This means that $60 \%$ of current drugs are made from herbal remedies. Indeed, medicinal plants represent an immense source of phenolic compounds (phenolic acids, flavonoids, tannins) and others (alkaloids, coumarins...). Isolation of chemical species from medicinal plants can be a prolific resource for new drugs (Karmakar et al., 2011). In order to help and protect populations, it is necessary to study the properties of commonly used medicinal plants. It is with this in mind that our work has focused on the chemical screening and evaluation of the antiradical activity of the methanolic extract of Annickia chlorantha (Annonaceae). This plant is used for its therapeutic properties, in particular in the treatment of malaria, fever growth, typhoid fever and hepatic infections as some forms of ulcers 
(Olamide and Mathew, 2013; Olivier et al., 2015).However, despite the use of this plant in traditional medicine, no study has been carried out on the Gabonese plant.

\section{Material Et Methods:-}

\section{Plant material:}

The trunk bark of Annickia chlorantha was collected in august2018between Oyane 4 and FourPlace in EstuaireProvincial. The fresh trunk bark was dried for about fifteen days protected from light in an air-conditioned room. It was powdered using an electric grinder (Flour Mills Nigeria, El MOTOR N ${ }^{\circ} 1827$ ). The resulting powder was stored at room temperature in a clear labeled packaging bag. The plant has been identified in the National Herbarium of Gabon.

\section{Preparation of methanolicextract:}

$200 \mathrm{ml}$ of methanol were added to $10 \mathrm{~g}$ of powder contained in an Erlenmeyer flask with a magnetic bar. After hermetically closing the Erlenmeyer flask, the mixture is left under magnetic stirring for 24 hours and then filtered using Whatman $\mathrm{N}^{\circ} 1$ filter paper. The filtrate was stored at $4^{\circ} \mathrm{C}$ until analysis.

\section{Qualitative Phytochemical analysis:}

Phytochemical screening of dry extracts was achieved through simple methods as described inCiulei, 1964 and Harborne, 1998.

\section{Determination of Total polyphenolscontent:}

The evaluation of the total polyphenols was carried out by the Folin-Ciocalteu method described by Singleton et al. (1999) and modified by MefouetAbessolo et al. (2021) on methanolic extract. Gallic acid was used as a standard to establish the standard range $(0-150 \mathrm{mg} / \mathrm{l})$. The results are expressed in $\mathrm{mg}$ of Gallic Acid Equivalent (QE) per $100 \mathrm{~g}$ of dry extract.

\section{Determination of Total flavonoidscontent:}

The total flavonoids are determined according to the method of Arvouet-Grant (1994) with some modifications. Quercetin was used as a standard to establish the standard range $(0-50 \mathrm{mg} / \mathrm{l})$. Results are expressed in mg of quercetin equivalent $(\mathrm{QE})$ per $100 \mathrm{~g}$ of dry extract.

\section{Evaluation of antiradical activity:}

Antiradical activity was determined by the ABTS method (Re et al., 1999). The antiradical activity of methanolic extract is deduced from its ability to inhibit ABTS $^{\circ+}$ compared to a reference antioxidant (gallic acid).The $\mathrm{ABTS}^{\circ+}$ radical ion is obtained by reacting the ABTS molecule $(7 \mathrm{mM})$ with potassium persulfate $(2.45 \mathrm{mM})$ in distilled water for 16 hours at room temperature and in sunlight. The ABTS $^{\bullet+}$ solution obtained is diluted with sodium phosphate buffer $(5 \mathrm{mM}, \mathrm{pH}=7.4)$, in order to obtain a stock solution having an initial absorbance value of between 0.65 and 0.70 at $734 \mathrm{~nm}$ (UV spectrophotometer).

The inhibitory effect of ABTS was calculated according to the following formula:

Anti-free radical activity $(\%)=[1-\mathrm{Ar} / \mathrm{Ai}] \times 100$

$\mathrm{Ar}=$ Absorbance remaining of $\mathrm{ABTS}^{\bullet+}$

$\mathrm{Ai}=$ Initial Absorbance of $\mathrm{ABTS}^{\circ+}$

\section{Results And Discussion:-}

\section{Phytochemical screening:}

The phytochemical tests carried out on methanolic extract of trunk bark of Annickia chlorantha show the abundance presence of alkaloids, catechics tannins and polyphenols. There's also reducing compounds, flavonoids (flavones), sterols and coumarins (Table 1).

Some of these groups of compounds identified as alkaloids have several pharmacological activities, namely antimalarial (Uzor, 2020; Bribi, 2018), antibacterial (Kakpo et al., 2019), hepatoprotective (Jan et al., 2017). Some countries such as Cameroon have isolated aporphinic alkaloids (Wafo et al., 1999) and protoberberine alkaloids (Nyongbela et al., 2019) from Annickia chlorantha. Protoberberine alkaloids (palmatin, jatrorrhizine, columbamine) 
isolated from the stem bark have been combined to make a phytodrug (HEPAZOR ${ }^{\circledR}$ ) for the treatment of viral hepatitis (Nyongbela et al., 2019).

According tannins catechics, studies reveal antibacterial and antiviral activities with capacities to reduce blood pressure (Bele et al., 2010; Coșarcă et al., 2019). The presence of these important bioactive compounds indicates the medicinal value of Annickia chlorantha and could be at the origin of various activities revealed by the population and traditional healers.

Table 1:- Phytochemical composition of methanolic extractof the trunk bark of Annickia chlorantha.

\begin{tabular}{|c|c|c|}
\hline \multicolumn{2}{|c|}{ phytochemical compounds } & Extract \\
\hline \multicolumn{2}{|l|}{ Alkaloids } & ++ \\
\hline \multirow[t]{2}{*}{ Tannins } & Gallic & - \\
\hline & Catechic & ++ \\
\hline \multicolumn{2}{|l|}{ Saponosides } & - \\
\hline \multicolumn{2}{|c|}{ Reducing compounds } & + \\
\hline \multirow{3}{*}{ Flavonoids } & Flavones & + \\
\hline & Flavanones & - \\
\hline & Flavonols & - \\
\hline \multirow{2}{*}{$\begin{array}{l}\text { Sterols et } \\
\text { triterpenoides }\end{array}$} & Sterols & + \\
\hline & Terpenes & - \\
\hline \multicolumn{2}{|l|}{ Coumarins } & + \\
\hline \multicolumn{2}{|l|}{ Polyphenols } & ++ \\
\hline
\end{tabular}

(++):Abundance; (+):presence; (-): absence

Total Phenolic and Flavonoid contents:

The total phenol content was determined in comparison with a standard which is gallic acid. The Results (Table 2) were expressed in milligrams of gallic acid per 100 grams of dry matter (mg GAE/100 g DM), using the linear equation extract: $\mathrm{Y}=0,011 \mathrm{X}+0,0291$ (with $\mathrm{R}^{2}=0,9972$ ). Thus, total phenolic content is $309,18 \pm 38,06 \mathrm{mg}$ GAE/100 g DM.

The total flavonoid content was determined in comparison with quercetin. Results were expressed in milligram equivalent of quercetin per 100 grams of dry matter $(\mathrm{mg} \mathrm{EQ} / 100 \mathrm{~g}$ DM. using the linear equation $\mathrm{Y}=0.0258 \mathrm{X}+$ 0.043 (with $\mathrm{R}^{2}=0.9973$ ). Thus, total flavonoids content is $155,16 \pm 21,06 \mathrm{mg} \mathrm{QE} / 100 \mathrm{~g} \mathrm{DM}$.

Table 2:- Total phenolic and flavonoids contents in methanolic extract of trunk bark of Annickia chlorantha.

\begin{tabular}{|l|l|l|}
\hline & $\begin{array}{l}\text { Total phenolic content } \\
(\mathrm{mg} \text { GAE/100 g DM) }\end{array}$ & $\begin{array}{l}\text { Flavonoids content } \\
(\mathrm{mg} \mathrm{QE} / 100 \mathrm{~g} \mathrm{DM})\end{array}$ \\
\hline Extract & $309.18 \pm 38,06$ & $155.16 \pm 21,06$ \\
\hline
\end{tabular}

In Nigeria, Olanlokun and Akomolafe (2013) showed that the methanolic extract has a high content of total polyphenols $(838.03 \pm 34.40 \mathrm{mg} \mathrm{GAE} / \mathrm{g}$ of extract) and an appreciable content of total flavonoids $(140 \pm 0.008 \mathrm{mg}$ QE/g of extract). In Cameroon, Djimeli et al. (2017) obtained a total polyphenol content of $690.53 \pm 23.597 \mathrm{mg}$ $\mathrm{GAE} / \mathrm{g}$ of extract. In view of these results, the stem bark of Annickia chlorantha from Nigeria and Cameroon are more rich ontotal polyphenolsthanthe trunk bark of Annickia chlorantha from Gabon.However, the trunk bark of the Gabonese plant contains more total flavonoids.

\section{Antiradical activity:}

The antiradical activities of gallic acid and methanolic extract from the trunk bark of Annickia chlorantha were reported in Figures 1 and 2.

For the gallic acid (Figure 1), the percentage of the antiradical activity increases with the concentration after 6 minutes of incubation. The antiradical activity reaches $100 \%$ after 6 minutes of incubation for concentrations greater than or equal to $0.84 \mu \mathrm{g} / \mathrm{ml}$. 
However, regarding the methanolic extract, the anti-radical activity was limited to $81.58 \% \pm 1.25$ without disappearance of the $\mathrm{ABTS}^{\circ+}$ radical after 6 minutes of incubation (Figure 2).

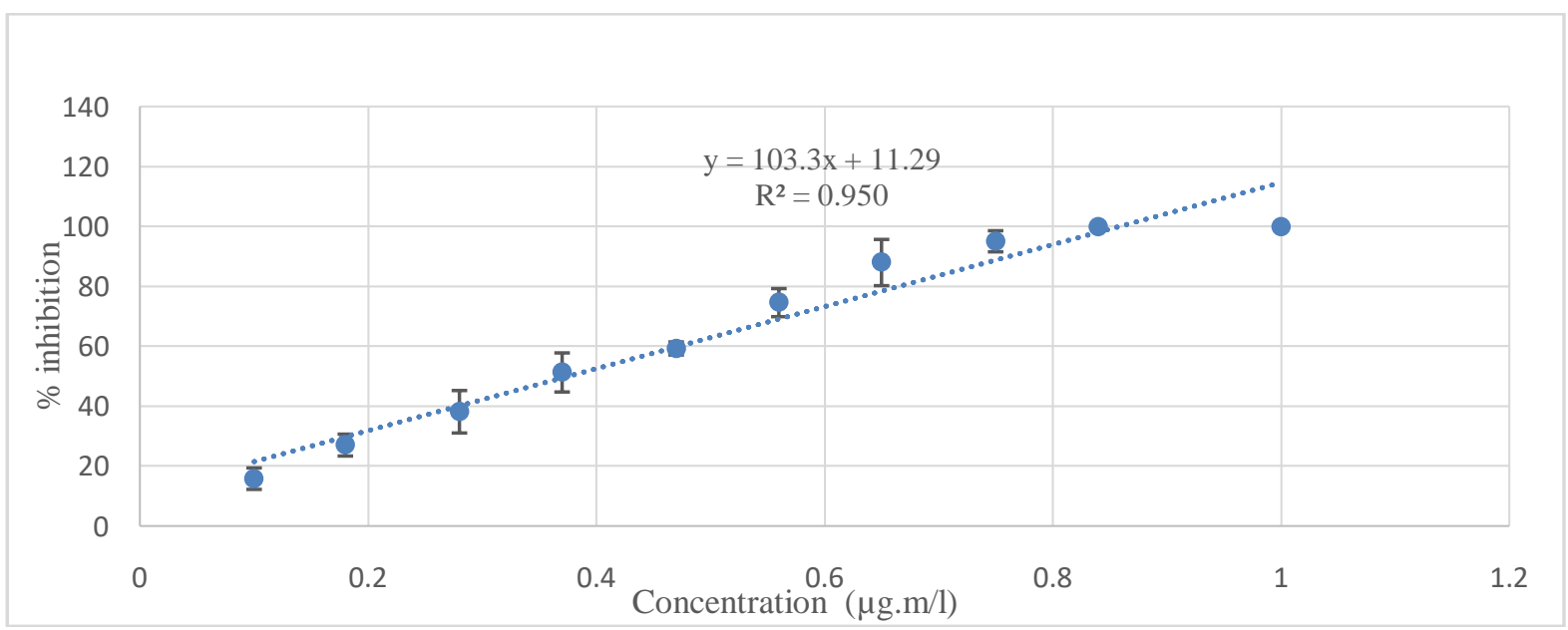

Figure 1:- Percentage ofGallic acid inhibition curve at different concentrations.

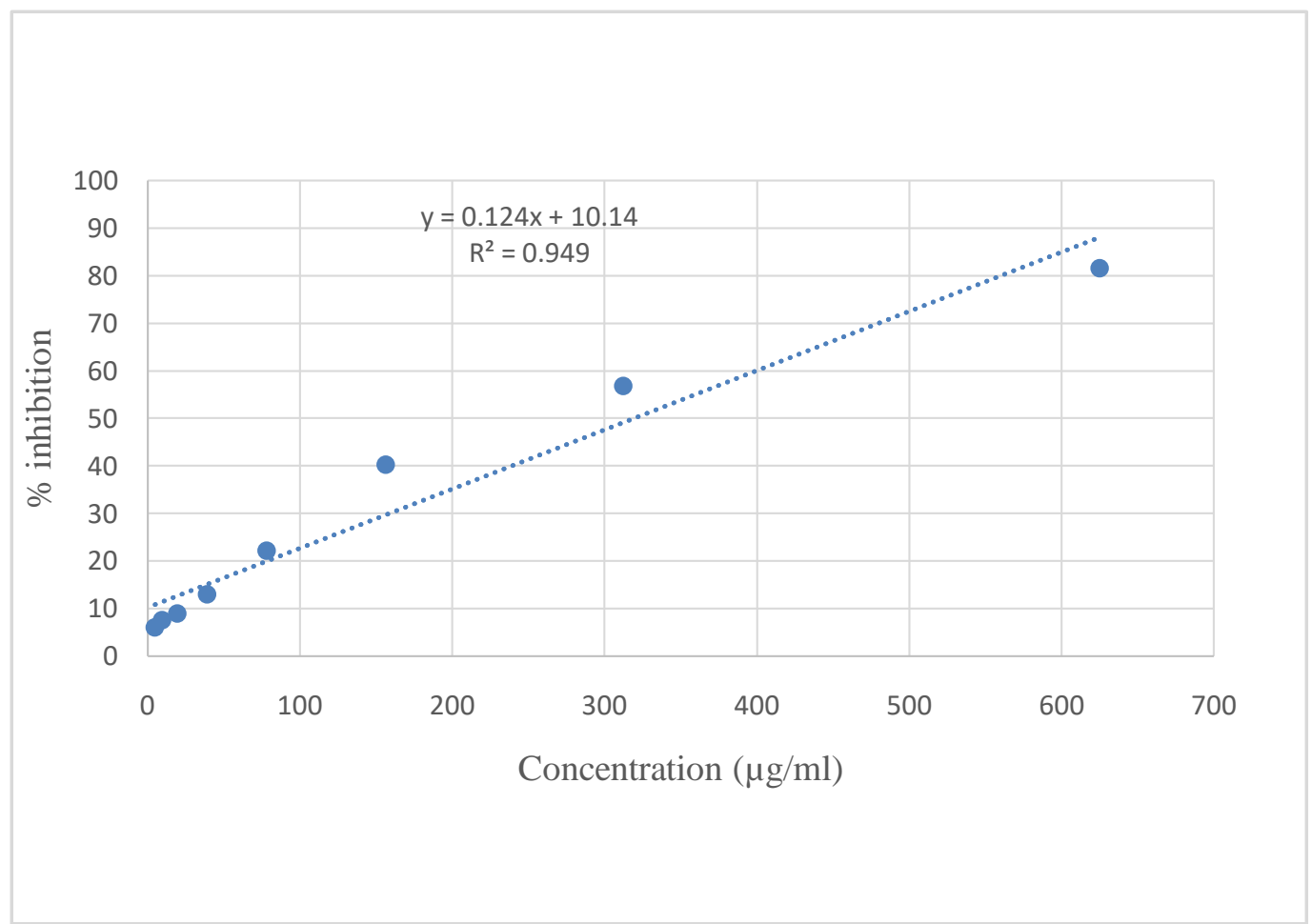

Figure 2:- Percentage of methanolicextractinhibition curve at different concentrations.

According absence of disappearance of ABTS, we can deduce that the methanolic extract of the bark of Annickia chlorantha has no antioxidant activity or that it's very weak. This result could be explained by the low contents of polyphenols and total flavonoids obtained.

\section{Conclusion:-}

This study is the first carried out on Annickia chlorantha from Gabon. Through this study, the phytochemical composition of the methanolic extract of the trunk bark. revealed thepresence of alkaloids, catechics tannins, reducing compounds, flavonoids (flavones), sterols and coumarins. These compounds can explain the use of this 
plant for the treatment of many pathologies. Furthermore, by the ABTS method, this methanolic extract showed weak anti-free radical activity. A result which could be explained by the low content of polyphenols.

\section{Knowlegment:-}

The authors appreciate the help and participation of Doctor Marie-Andrée N'NEGUE especially for her contribution related to the antiradical activity.

\section{References:-}

1. Arvouet-Grant A, Vennat B, Pourrat A, Legret P. 1994: Standardisation d'un extrait de propolis et identification des principaux constituants. J. Pharm. Belg.49(6):462-468.

2. Bele AA, Jadhav VM, Kadam VJ. 2010 : Potential of Tannnins: A Review. Asian J Plant Sci. 9(4): 209-214.

3. Bribi N. 2018: Pharmacological activity of Alkaloids: A Review. Asian J. Bot. 1:1-6. doi:10.63019/ajb.v1i2.467

4. Coșarcă S, Tanase C, Muntean DL. 2019: Therapeutic aspects of catechin and its derivatives - an update. Acta Bio. Marisiensis. 2(1): 21-29. DOI: 10.2478/abmj-2019-0003

5. Djimeli MN, MendimiNkodo JM, Njateng GSS, Fokunang C, Kodjio N, Atsafack SS, NkueteLonfouo AH, Sokoudjou JB, Guewo-Fokeng M, Gatsing D. 2017:InvitroAntioxidant and Anti-salmonellalactivities of StemBarkextracts of Enantiachlorantha (Annonaceae).Res. J. Pharm. Biol. Chem. Sci. 8(6): 1-12.

6. Harborne JB. 1998: Phytochemical method, AGuide to Modern technique of Plant Analysis (3rd Edition). Chapman and Hall Edition : New York.

7. Jan NU, Ahmad B, Ali S, Adhikari A, Ali A, Jahan A, Ali A, Ali H. 2017: Steroidal Alkaloids as an Emerging Therapeutic Alternative for Investigation of Their Immunosuppressive and Hepatoprotective Potential. Front. Pharmacol. 8(114): 1-13. Doi: 10.3389/fphar.2017.00114

8. Kakpo AB, Yayi E, Lenta BN, Assogba FM, Toklo PM, Boyom FF, Baba-Moussa L, Gbenou J. 2019: Phytochemistry and anti-bacterial activity of thirteen plants used in traditional medicine to treat typhoid fever in Benin. Int. J. Innov. Appl. Stud. 25(3):1034-1047.

9. Karmakar I, Dolai N, Saha P, Sarkar N, Bala A, KantiHaldar P. (2011): Scavenging activity of Curcuma caesia rhizome against reactive oxygen and nitrogen species. Orient. Pharm. Exp. Med., 11:221-228.

10. Mefouet Abessolo DD, Abogo Mebale AJ, Ombouma JG. 2021: Phytochemical composition, total polyphenols and total flavonoids content of the aqueous extract of Raphia hookeri mesocarp from Mebole village (Gabon). Int. J. Chem. Studies.9(4):01-05.

11. Newmann D, Cragg GM. (2007): Natural products as sources of new drugs over the last 25 years. J. Nat. Prod., 70:461-477.

12. NgonoNgane RA, KoangaMogtomo ML, TchindaTiabou A, Magnifouet Nana H, MotsoChieffo PR, MballaBounou Z, EbelleEtame RM, Ndifor F, Biyiti L, AmvamZollo PH.2011: Ethnobotanical survey of some Cameroonian plants used for treatment of viral diseases. Afr. J. Plant Sci. 5(1):15-21.

13. Nyongbela KD, Samje M, Awantu AF, Tiku TE, Cho-Ngwa F. 2019: Evaluation of anti-onchocercal activity of pseudopalmatine, a quaternary protoberberine alkaloid of Enantiachlorantha (Syn. Annickia chlorantha). J. Cameroon Acad. Sci. 14(3):171-180.

14. Olamide E, Mathew O. 2013: Phytochemical and acute toxicity of ethanolic extract of Enantiachlorantha (oliv) stem bark in albino rats. Interdiscip. Toxicol. 6(3):145-51.

15. Olanlokun JO, Akomolafe SF. 2013: Antioxidant potentials of various solvent extracts from

16. stem bark of Enantiachlorantha. J. Biomed. Eng. 6(9): 877-884.

17. Olivier DK, VanVuuren SF, Moteetee AN. 2015: Annickia affinis and A. chlorantha (Enantiachlorantha) - A reviewof two closelyrelatedmedicinalplantsfromtropicalAfrica. J. Ethnopharmacol. 176:438-462.

18. Re R, Pellegrini N, Proteggente A, Yang M, Rice-Evans C. 1999: Antioxidant activity applying an improved ABTS radical cationdecolorization assay. Free Radic. Biol. Med.26:1231-7.

19. Singleton VL, Orthofer R, Lamuela-Raventós RM. 1999: Analysis of total phenols and other oxidation substrates and antioxidants by means of folin-ciocalteu reagent. Meth. Enzymol. 299:152-178.

20. Uzor PF. 2020: Alkaloids from Plants with Antimalarial Activity: A Review of Recent Studies.Evid. Based Complement. Altern. Med.Article ID 8749083. https://doi.org/10.1155/2020/8749083

21. Wafo P, Nyasse B, Fontaine C, Sondengam BL. 1999: Aporphine alkaloids from Enantia chlorantha. Fitoterapia. 70:157-160. 